\title{
FAMÍlIA E CONJUGALIDADE: O SINTOMA DOS FILHOS FRENTE À IMATURIDADE DO CASAL PARENTAL
}

\author{
Marina Fibe de Cicco* \\ Maria Lucia S. C. Paiva** \\ Isabel Cristina Gomes***
}

\section{RESUMO}

$\mathrm{O}$ artigo trata das inter-relaçóes entre a imaturidade dos pais e o processo de criação dos filhos. Baseia-se no relato de uma experiência clínica onde a formação de sintomas nas crianças era decorrente da dificuldade do casal parental na constituição da conjugalidade e no estabelecimento dos papéis de cada um no interior da família, além de forte interferência das famílias de origem. O referencial teórico winnicottiano é utilizado, traçando-se um paralelo entre o desenvolvimento da criança e o da família e buscando uma articulação com as características da sociedade atual.

Palavras-chave: casal, sintoma, criança, família

\section{AbSTRACT}

FAMILY AND CONJUGALITY: THE SYMPTOM OF THE CHILDREN FACING THE IMMATURITY OF THE PARENTS

The article deals with the relationship between parents' immaturity and the process of children's upbringing. It is based on the report of a clinical experience where symptom formation in the children was due to the parental couple's difficulty in the constitution of conjugality and in the establishment of their respective roles within the family, along with a strong interference from the extended family. Winnicott's theory is used to compare the development of the child with that of the family and to articulate it with characteristics of current society.

Keywords: couple, symptom, child, family

* Bolsista de iniciação científica (PIBIC /CNPq).

** Doutoranda do Programa de Pós-Graduação em Psicologia Clinica do IPUSP, Bolsista CAPES.

*** Profa. Doutora do Departamento de Psicologia Clínica e do Programa de Pós-Graduação em Psicologia Clinica do IPUSP. 
O estudo da família e dos modelos de relações conjugais da pós-modernidade é fundamental para a compreensão das mudanças ocorridas nas últimas décadas e de suas implicações para o desenvolvimento e amadurecimento dos indivíduos nos contextos familiares atuais.

Winnicott (1960/1997) discute o papel da família no estabelecimento da saúde individual, questionando a capacidade do homem de atingir a maturidade emocional fora do contexto familiar. O autor define "maturidade" como sinônimo de saúde, dando-lhe o "status" de processo (um ir e vir) que acompanha o indivíduo ao longo de toda sua vida, denominando esse estado de maturidade relativa.

Tomando-se como ponto de partida o fato de Winnicott atribuir um peso muito grande à família, como formadora e propiciadora de um desenvolvimento saudável ao ser humano, este trabalho propõe-se refletir sobre as situações onde nem sempre é possível encontrar esse ambiente saudável e acolhedor no interior da família.

O próprio autor afirma que o casamento e a constituição de uma família nem sempre são sinais de maturidade parental (Winnicott, 1960/1997: 64) e que, sendo assim, "Dentre homens e mulheres imaturos que se casam, muitos encontram na família motivo para grande alegria e alívio; mas não nos surpreendamos se o crescimento de seus próprios filhos os desafiar a dar continuidade ao próprio crescimento, que se sustara à época da adolescência" (op. cit.: 65).

$\mathrm{Ou}$, alternativa que é o propósito deste artigo abordar, a imaturidade ${ }^{1}$ do casal parental bloqueia o crescimento e desenvolvimento saudável de toda a família assim constituída, gerando sintomas nos filhos. Winnicott (1960/1997) destaca ainda que, em relação ao casamento, este deve ser, ao mesmo tempo, uma ruptura em relação aos pais e à família de origem e um prolongamento da idéia orientadora da estrutura familiar.

Encontramos, no material clínico que será discutido posteriormente, uma confirmação dessas idéias de Winnicott, ou seja, temos um casal que não se constituíra como tal quando firmou o casamento, pois ambos mantinham ligações muito fortes com suas famílias de origem, mantendo-se juntos por encontrarem no parceiro soluções para problemas concretos, ao invés de se unirem por desejo de compartilhar uma nova vida e construir uma nova família. Dessa forma, o nascimento dos filhos apenas reforçou a falta de coesão do casal, que não mantinha um espaço para si mesmo, produzindo uma dinâmica que dificultava ainda mais sua saída da condição de filhos ou adolescentes.

A apresentação do caso clínico ilustrará o quanto a saúde da família e sua capacidade de promoção de crescimento de seus membros dependem da qualida- 
de da relação estabelecida pelo casal parental. Muitas contribuições podem ser feitas ao entendimento dos sintomas infantis quando o olhar do profissional se volta para o casal e para o modo como chega à clínica.

Gomes $(1998,2002)$ destaca que uma das formas de o casal entrar em contato com seus conflitos é através do sintoma de seus filhos, que denuncia a dinâmica do casal. Tal sintoma constitui um meio auxiliar para os pais chegarem à clínica e se voltarem para o entendimento da dinâmica conjugal. Em muitos casos, o sintoma de um filho pode expressar um conflito conjugal e/ou familiar ou ainda uma desestruturação destas relações. Nesse caso, as crianças funcionam como bodes expiatórios. Sugere-se, então, uma ampliação do olhar do clínico para o entendimento desses sintomas, englobando uma outra forma de encaminhamento para o caso, onde toda a família se veja envolvida e cuidada; por exemplo, a escolha por uma terapia familiar.

Esta proposta interventiva pode ser indicada, segundo Soifer (1983), em situações de crise na família, como desemprego, mudanças culturais, luto... Gomes $(1998,2003)$ aponta a escolha pela terapia de casal como uma terapêutica mais eficaz nos casos em que o sintoma da criança é decorrente da problemática do casal parental, acreditando que esse tipo de intervenção clínica pode exercer um efeito não só curativo, mas também preventivo, atingindo principalmente os filhos e, conseqüentemente, a família como um todo.

A autora enfatiza ainda que discutir as características do casamento hoje vem complementar a visão do clínico que pretende trabalhar na área dos conflitos conjugais e familiares. Féres-Carneiro (2001) destaca que "o casamento contemporâneo representa uma relação de intensa significação na vida dos indivíduos, tendo em vista que envolve um alto grau de intimidade e um grande investimento afetivo" (Féres-Carneiro, 2001: 67).

Ao mesmo tempo que esta relação demanda intenso investimento, tanto de tempo quanto afetivo, por parte dos cônjuges, as características individualistas do casamento nunca foram tão fortes quanto na sociedade atual. $\mathrm{O}$ aumento das expectativas e a idealização extremada do outro provocam tensões e conflitos na relação conjugal, onde o parceiro é desejado por inteiro.

Gomes e Paiva (2003) sustentam a idéia de que o casamento na sociedade atual pode ser uma possibilidade de holding, mesmo havendo um alto grau de imaturidade e individualismo inerente ao mundo pós-moderno. Utilizando o referencial winnicottiano, as autoras pontuam que tanto o casamento quanto a família podem se constituir ou não como espaço de maturidade parental, onde haja contínuo crescimento de todos os envolvidos. 
Em um contexto familiar saudável, o sujeito poderia se retroalimentar para encarar os desafios de cada dia de forma mais segura. Esta questão é central para a discussão do material clínico que será apresentado mais adiante, pois, ao chegar à terapia, o casal apresentou-se como incapaz de constituir uma família própria que promovesse tanto o desenvolvimento dos cônjuges quanto o crescimento dos filhos. O trabalho com eles visou à tomada de consciência de seus novos papéis e à constituição de sua conjugalidade, de modo que a relação com seus filhos se tornasse mais sólida e que pudessem estar aptos para propiciarem um ambiente familiar saudável.

Winnicott (1958/1990) descreveu a possibilidade que o sujeito tem de permanecer só, mas em um estado de tranqüilidade. Segundo ele, essa possibilidade ou é adquirida no início da vida, ou pode ser desenvolvida através de um processo mais sofisticado, após o estabelecimento de relações triádicas. Atualmente, é possível perceber que as pessoas se sentem muito sozinhas e esse estágio do desenvolvimento emocional não foi adquirido.

A saída de um filho da casa dos genitores implica, tanto para os filhos como para os pais, a "capacidade para estar só". Casar e formar uma família exige que os cônjuges tenham desenvolvido essa capacidade, que é um estado do desenvolvimento emocional que está vinculado ao amadurecimento e ao processo do desenvolvimento para a autonomia.

Outros teóricos como Niccoló (1995), que estudam os mecanismos intrínsecos à escolha dos pares conjugais e à formação da família, apontam a importância da influência da dinâmica do casal parental de origem no estabelecimento do funcionamento da família atual e sua maneira de criar os filhos.

O conceito de adaptabilidade, descrito por Walsh (2002), é particularmente útil para a reflexão teórico-clínica que nos propomos fazer neste artigo. Segundo a autora, a adaptabilidade tem relação com o equilíbrio entre a manutenção de uma estrutura estável e ao mesmo tempo flexível em resposta às mudanças de vida, constituindo-se como um dos requisitos principais para o bom funcionamento de um casal e de uma família. Walsh afirma ainda que, a cada transição de uma fase da vida conjugal à outra, o contrato inconscientemente estabelecido pelo casal deve ser levado em consideração e renegociado.

A autora destaca que, durante a fase de sedução, os casais deveriam ser mais sagazes e perspicazes no planejamento do casamento e que, em geral, não se recorre à terapia até que os problemas tenham se tornado graves ou crônicos, ou que um dos cônjuges decida divorciar-se. A cada importante transformação (como o nascimento de um filho), o contrato tácito estabelecido pelos cônjuges deve ser 
submetido a mudanças para suportar as necessidades de reorganização dessa vida conjugal.

Assim, procuraremos elucidar, neste momento, através da apresentação e discussão de um caso clínico, as questôes levantadas nos parágrafos anteriores. Serão abordadas, principalmente, as conseqüências da imaturidade dos pais na criação dos filhos. Para tanto, a discussão da dinâmica do casal e dos padrões de relaçôes atuais mostra-se de fundamental importância, pois suas influências se fazem sentir na qualidade dos vínculos estabelecidos pelos cônjuges. Desta forma, espera-se ampliar a compreensão dos sintomas das crianças e levantar novas questões para pesquisas da prática clínica contemporânea.

\section{APRESENTAÇÃO DO MATERIAL CLÍNICO}

Durante um ano e meio, foi realizado, na Clínica-Escola do IPUSP, o atendimento de um casal encaminhado para o projeto de pesquisa: Atendimento Breve a Casais e Famílias, na Abordagem Psicanalitica².

$\mathrm{Ana}^{3}, 31$ anos, procurou a clínica com seu marido Bruno, de 30 anos, em busca de um atendimento psicológico para a filha Laura, de 4 anos. A queixa era que Laura, então com 3 anos, não lhes obedecia, não aceitava o "não" nem qualquer limite, e que não haviam conseguido colocá-la na escola após cinco tentativas frustradas. Em uma destas tentativas, a menina ficou muito doente e a mãe, sentindo-se culpada, parou de trabalhar, achando que deveria estar mais com sua filha. Desde então, não voltou a procurar emprego. $\mathrm{O}$ pai dizia que a menina discutia com ele como se fossem irmãos. Os três e a filha mais nova do casal, Júlia, de seis meses, moravam com a mãe de Bruno desde que Ana perdeu seu emprego em Itatiba. Desde então, o casal não pôde mais viver no interior, tendo que voltar para São Paulo e morar em Cotia com a sogra da esposa.

Ana dizia que tanto sua família quanto a de Bruno davam sugestões na educação de Laura, desautorizando-os. Para o casal, suas famílias de origem sentiamse no direito de fazê-lo porque os ajudavam financeiramente. Eles percebiam também que a filha era satisfeita em seus desejos pelos familiares, o que desqualificava a autoridade materna.

Nessa primeira entrevista, surgiram temas importantes que delinearam todo o processo terapêutico, destacando-se a maneira pela qual o casal se colocava como dependente e desprovido de autonomia - tanto perante a filha quanto perante as famílias de origem.

Nas entrevistas subseqüentes, conforme o casal foi contando a história de como a relação conjugal se constituiu, a hipótese de que havia uma dificuldade no 
processo de aquisição da maturidade emocional de cada cônjuge foi se confirmando. Havia uma mistura de papéis na família - os pais não conseguiam exercer a paternidade e a maternidade devido à forte ligação que tinham com as famílias de origem, principalmente suas mães. O casal comportava-se como filhos e não tinha consciência de seu papel, nem o exercia enquanto construtor de uma nova família.

Ana enfatizava que a mudança para uma casa na qual pudesse viver apenas com o marido e suas filhas resolveria todos os problemas, "pois, quando estamos só nós quatro, fica tudo ótimo" (sic). Ela imaginava que as questões realmente se resolveriam através de uma mudança concreta de casa. Entretanto, podia-se perceber que as dificuldades emocionais de construir uma família iam além do espaço físico.

Ao ser explicitada a dinâmica familiar, o casal aceitou a proposta de que o atendimento continuasse em um enquadre de terapia de casal, sem que fosse preciso ver a menina. Desde o início da terapia, o casal falava da filha como se ela os dominasse, sem ter idéia de que, diante de uma menina de três anos, poderiam manter um "não" contínuo, independente da reação dela. Era como se Laura já tivesse entendido que conseguiria tirar a mãe de seu lugar e que certos comportamentos seus eliminavam a autoridade de seus pais. Os pais não traziam nada que estivesse comprometido no desenvolvimento de Laura, apenas comportamentos reacionais ao ambiente externo.

Com o transcorrer das sessōes com o casal, a filha deixa de ser o foco. Muitas vezes comentavam sobre o cotidiano e a respeito da dificuldade que tinham em cuidar das crianças e manter o espaço do casal ao mesmo tempo. Eles não tinham a dimensão do que significava ter filhos, não entendiam que sua vida mudara, sendo preciso, então, coordenarem o espaço para cada um: o de casal e o de pais.

A esposa apresentava comportamentos que permitiam pensar ser sua atitude similar à de uma adolescente. Isto pôde ser percebido quando ela contou que largara seu emprego porque não concordara com algumas atitudes de seu chefe. Perseguira um "ideal”, mas não pensara nas conseqüências de sua atitude impulsiva para a vida do casal e da filha que esperava, já que, na época, estava grávida de Laura. Além disso, Ana falava do marido, muitas vezes, como se ele fosse uma "parte dela", isto é, ela procurava controlá-lo e programar todas as atividades familiares de acordo com seus interesses, dizendo que ele faria de tudo para vêla feliz.

A maioria dos assuntos abordados durante a psicoterapia dizia respeito às famílias de cada um, especialmente à mãe dele e à mãe dela; pouco falavam da relação e de problemas conjugais. A forma de conduzirem as sessōes confirmava 
que a constituição do casal era dificultada pela imaturidade de ambos, dada a ligação muito forte que mantinham com suas famílias de origem. Ana queixava-se muito da sogra e, ao longo do processo terapêutico, ficou claro que muitas de suas reclamações e seu desejo de mudar-se e ter sua própria casa estavam fortemente relacionados à vontade de se verem livres dessa mulher, também mãe e rival edípica.

Procurou-se dispensar especial atenção a Bruno e às suas reações diante da forma como Ana lidava e falava de sua sogra, pois a tendência dele era sempre a de ficar quieto, sem manifestar-se, o que também pôde ser mais bem compreendido quando tivemos mais dados sobre sua história de vida, que era marcada pela ausência do pai e pelo controle da mãe.

Ana reclamava, muitas vezes, da forma grosseira como seu marido a tratava. Ela esperava com muita ansiedade os dias de folga dele; entretanto, Bruno ficava mal-humorado. Ele parecia repetir com a esposa a mesma relação que estabelecia com sua mãe - ambas esperavam que ele atendesse a todas as suas expectativas -, sem poder se constituir como sujeito dos seus próprios desejos e açôes, o que tornava mais difícil, para ele, a tarefa de construir uma família. A dificuldade de Bruno de lidar com a filha estava relacionada ao fato de ele ainda ser "muito mais filho do que pai”, tendo, por isso, dúvidas quanto aos limites e alcances de seu papel na família que constituíra com a esposa.

Ana tinha problemas de relacionamento com sua sogra que a impediam de aceitar as condições em que sua família vivia. Por isso, enfatizava seu desejo de ter sua própria casa e tentava obter o apoio de Bruno para seus planos. Este, no entanto, tinha maior maturidade no sentido de não querer abandonar a segurança da casa de sua mãe, onde conseguia poupar boa parte de seu salário, e por isso relutava em acatar as vontades da esposa, dizendo sempre que a mudança só seria possível se ela também tivesse um emprego.

Bruno também começou a manifestar mais suas opiniões nos momentos em que Ana falava de sua mãe. Dizia que aquela preocupação da esposa era exagerada e que sua mãe era diferente da de Ana; não adiantava ela querer comparar as duas ou exigir que a sogra fosse como sua própria mãe. Além disso, dizia não entender o motivo por que a esposa se incomodava tanto com as atitudes de sua mãe em relação aos cuidados com a casa e com certos comentários que fazia em relação a Ana. Esta rebatia, dizendo que "para ele está sempre tudo bem, a mãe dele fala mal dele e quem se importa sou eu". Esta questão foi trabalhada com Ana, mas o conflito só foi resolvido quando o casal mudou-se para um apartamento alugado, após uma séria briga entre Ana e a sogra. Novamente surgia uma situação concreta que confirmava as pontuaçôes feitas até então: Ana, imatura, provocava uma grande mudança na vida da família, sem haver feito planejamento algum. 
Embora o marido pretendesse sair da casa da mãe no ano seguinte e estivesse se preparando financeiramente para isso, era a esposa quem, mais uma vez, ditava os rumos da vida do casal e das filhas. Isto também foi discutido em terapia, mas o tema logo deu lugar às transformações decorrentes da mudança. Ana dizia-se muito feliz e destacava o quanto as filhas gostavam da nova casa. Bruno, por sua vez, mantinha-se reservado e guardava certo rancor por ter tido que se submeter, mais uma vez, à vontade da mulher.

Quando, no fim do ano, Ana passou no vestibular para Pedagogia, em uma faculdade particular, a questão ressurgiu. Bruno não se sentia seguro o suficiente para pagar as mensalidades dos primeiros seis meses da faculdade e mostrava que, desta vez, pretendia fazer valer sua vontade de manter certa estabilidade financeira, ainda que às custas do estudo de Ana. Ela, apesar de insatisfeita com a postura do marido, estava disposta a trancar a faculdade no primeiro semestre. Isto, no entanto, não foi necessário, pois Ana conseguiu emprego em uma escola e descobriu um curso mais curto que a habilitaria a dar aulas, pois já era formada em Matemática.

Atualmente, ela está contribuindo com o pagamento das despesas da casa e Bruno tem ajudado bastante com as tarefas domésticas. A filha mais nova do casal está se desenvolvendo muito bem e Laura, agora com 5 anos e meio, além de estar em tratamento fonoaudiológico para corrigir alguns erros de articulação das palavras, finalmente entrou na escola, onde, até o momento, não apresentou nenhum problema.

\section{DisCUSSÃO E CONSIDERAÇÓES}

A história do casal confirma a hipótese de que não havia uma conjugalidade de fato constituída no momento em que se casaram. Ana, que sempre ditara os rumos da vida dos dois, estava em conflito, pois morava fora de casa há alguns anos e não queria voltar a viver com sua família de origem sob condição alguma. Sem ter para onde ir, após a dona da casa onde morava vender o imóvel, decidiu casar-se com Bruno e assim aconteceu. A opção pelo casamento em Ana vem, principalmente, para satisfazer uma motivação inconsciente: a necessidade de se separar fisicamente de sua família de origem, já que psiquicamente não conseguia fazê-lo, suplantando o desejo (físico e afetivo) de estar e viver com um marido.

Pouco tempo depois, ambos ficaram desempregados, exatamente no momento em que mais precisavam de segurança financeira. Ana estava grávida e, ao pedir demissão, demonstrou sua inconsciência em relação às mudanças que os filhos trariam para suas vidas e às responsabilidades derivadas dos papéis de pai e 
mãe. Criaram uma situação que os tornava novamente dependentes das famílias de origem. Este fato confirma a permanência de Ana e Bruno nas posições de filhos dependentes. A interferência direta da mãe de Bruno na vida do casal gerava conflitos entre as duas mulheres, que aumentaram à medida que o tempo passava e contribuíram imensamente para que Laura passasse a apresentar determinados comportamentos sintomáticos.

Ana insistia que a filha ficava tranqüila quando estava apenas com ela, alterando-se com a chegada de terceiros. A presença da avó certamente indicava "conflito" para Laura, aumentando sua agitação. A tendência da menina era a de imitar comportamentos da mãe, que sempre fora autoritário, e aborrecer-se quando seus desejos não eram satisfeitos. Ao mesmo tempo, Ana continuava muito dependente das opiniōes do resto de sua família, que se sentia no direito de interferir na educação das meninas porque as ajudava financeiramente. A imaturidade de Ana, definida de acordo com o referencial winnicottiano, que se manifestava pelo fato de comportar-se como filha muito mais do que como mãe, a impedia de ter a segurança necessária para impor os limites a Laura e sustentar o "não", quando necessário. As questões da história dela, especialmente de sua relação com a própria mãe, a levavam a querer viver com as filhas experiências que não tinha tido e depositar nelas todas as suas expectativas.

A confusão de papéis também era marcante no caso de Bruno, que não tinha consciência de sua tarefa de pai, nem um modelo paterno a seguir, não estando emocionalmente pronto para exercer essa função. À medida que o trabalho terapêutico evoluía e esses aspectos da história e da postura do casal eram esclarecidos e elaborados, as queixas sobre Laura diminuíram a ponto de raramente falarem da filha durante as sessões. No entanto, Ana e Bruno nunca abordavam temas envolvendo o relacionamento conjugal, o que indicava falta de uma conjugalidade bem estruturada. Eles falavam predominantemente das relaçôes com suas famílias de origem e dos conflitos decorrentes destas, além de contarem sobre suas dificuldades financeiras. Isto também foi apontado, aumentando a consciência do casal sobre a situação que vivia.

$\mathrm{Na}$ atualidade, o casal não depende mais das respectivas famílias de origem; a independência financeira os tem ajudado a caminhar rumo à independência emocional. Bruno passou a dividir o espaço das sessōes com Ana e adquiriu mais segurança para exercer os papéis de provedor e pai. Ana também percebeu que não poderia se satisfazer totalmente somente cuidando das filhas, voltou a trabalhar e incentiva o marido a estudar.

Este relato clínico demonstra o quanto a falta de planejamento na estruturação da vida familiar, derivada da imaturidade dos cônjuges, pode ter conseqüên- 
cias para a criação dos filhos. Dada a complexidade da vida cotidiana, a clareza e a coerência são essenciais para a ordem, a previsibilidade e o cumprimento das tarefas, enquanto as crises e eventuais variaçôes inesperadas na rotina exigem flexibilidade e tolerância para o caos que ocasionalmente pode se produzir (Walsh, 2002).

O conceito de membrana do casal apresentado por Niccoló (1995) é útil porque "permite distinguir o que os membros do casal, em sua colusão, contrataram inconscientemente que vá ficar dentro ou ser deixado de fora”. A membrana que contém o casal "como uma pele" pode ser definida por aspectos externos a ele, como no caso de Ana e Bruno, em que as fronteiras se estendiam às famílias de origem. Quando isto ocorre, a falta de um destes aspectos ou a ruptura da membrana, causada por algum evento transformador, podem gerar uma crise no casal, a qual só poderá ser superada se houver uma renegociação do contrato inconscientemente firmado. A conjugalidade mal estruturada torna ainda mais difícil a adaptação a mudanças e a transformações decorrentes de eventos importantes, favorecendo o surgimento de conflitos que atingem toda a família.

Pode-se pensar que essa dificuldade de estruturar uma membrana conjugal deve-se à imaturidade dos cônjuges de se constituírem como indivíduos separados de seus pais. É possível inferir que a "capacidade para estar só", como Winnicott (1958/1990) mencionou, não foi adquirida nas etapas iniciais do desenvolvimento emocional de cada um, ocasionando, na vida adulta, a impossibilidade de gerar um ambiente familiar saudável.

Segundo Walsh (2002), em qualquer estágio do ciclo vital em que se encontre um casal, ele pode ser ajudado por um terapeuta a pensar e planejar, esclarecer suas propostas, expectativas e as do parceiro, elaborando de modo mais explícito o contrato que mantém a relação. Ana e Bruno, por exemplo, nunca haviam renegociado o contrato conjugal, como seria saudável em situações como as de desemprego, nascimento das filhas e mudanças de casa.

Assim, a intervenção terapêutica se deu no sentido da renegociação do contrato, abrindo um espaço para a construção da conjugalidade e o exercício da parentalidade, fazendo com que o casal, paulatinamente, ocupasse o lugar de "sustentáculo" da família constituída. 


\section{REFERÊNCIAS BIBLIOGRÁFICAS}

Féres-Carneiro, T. (2001). Casamento contemporâneo: construção da identidade conjugal. Em Féres-Carneiro, T. (Org.). Casamento e família, do social à clínica (pp. 67-80). Rio de Janeiro: NAU.

Gomes, I. C. (1998). O sintoma da criança e a dinâmica do casal. São Paulo: Escuta. - (2002). A avaliação psicológica infantil denunciando os conflitos do casal parental. Em Anais do Vo Encontro Mineiro de Avaliação Psicológica (Vol. 1, pp. 25-28). São Paulo: Vetor. . (2003). Alcances e limites da psicoterapia psicanalítica com casais e famílias.

Em Féres-Carneiro, T. (Org.). Família e casal-Arranjos e demandas contemporâneas (pp. 215-224). Rio de Janeiro: PUC-Rio.

Gomes, I. C. e Paiva, M. L. S. C. (2003). Casamento e família no século XXI: possibilidade de holding? Psicologia em Estudo, 8 (número especial), 3-9.

Niccoló, A. (1995). O modelo psicanalítico de funcionamento do casal. Em Andolfi, M.; Angelo, C.; Saccu, C. (Orgs.). O casal em crise (pp. 75-90). São Paulo: Summus Editorial. Soifer, R. (1983). Psicodinamismos da família com crianças. Petrópolis: Editora Vozes.

Walsh, F. (2002). Casais saudáveis e casais disfuncionais: qual a diferença?. Em Andolfi, M. (org.). A crise do casal: uma perspectiva sistêmico-relacional (pp. 13-28). Porto Alegre: Artmed Editora.

Winnicott, D. (1958). A capacidade para estar só. Em Winnicott, D. W. O ambiente e os processos de maturação (pp. 31-37). Porto Alegre: Artes Médicas, 1990.

- (1960). Família e maturidade emocional. Em Winnicott, D. W. A família e o desenvolvimento individual (pp. 129-138). São Paulo: Martins Fontes, 1997.

\section{NotAS}

1 O termo "Imaturidade" será designado, nesse trabalho, como um estágio de não-aquisição (total ou parcial) da maturidade emocional relativa, conceito definido por Winnicott (1960/ 1997) para representar o processo inerente ao desenvolvimento emocional do indivíduo, visando um crescimento saudável.

2 Projeto de pesquisa coordenado pela Profa. Dra. Isabel Cristina Gomes.

3 Os nomes que aparecem neste artigo são fictícios para garantir o anonimato das pessoas envolvidas. 